\title{
AS CONTRIBUIÇÕES DA ANTROPOLOGIA NA SUPERAÇÃO DAS DUALIDADES
}

\author{
LAS CONTRIBUCIONES DE LA ANTROPOLOGÍA EN LA SUPERACIÓN DE LAS \\ DUALIDADES
}

THE CONTRIBUTIONS OF ANTHROPOLOGY IN OVERCOMING DUALITIES

\author{
Mariana Lombardi LUIZ ${ }^{1}$ \\ Raquel Lujan Hissa LEITE ${ }^{2}$
}

RESUMO: Este artigo propõe demonstrar o potencial e as contribuições da Antropologia enquanto ciência capaz de superar a matriz filosófica ocidental de pensar o mundo por categorias dicotômicas e excludentes. Para atingir esse objetivo, utilizou-se das obras dos antropólogos Bruno Latour, Eduardo Viveiros de Castro, Marilyn Strathern, Philippe Descola e Tim Ingold trazendo à tona outras formas de pensar e viver o mundo que não inscritas nas dualidades natureza versus cultura, humano versus não-humano, feminino versus masculino.

PALAVRAS-CHAVE: Filosofia ocidental. Dualidades. Potencial científico. Antropologia.

RESUMEN: Este artículo propone demostrar el potencial y las contribuciones de la Antropología como ciencia capaz de superar la matriz filosófica occidental de pensar el mundo por categorías dicotómicas y excluyentes. Para alcanzar ese objetivo, se utilizó de las obras de los antropólogos Bruno Latour, Eduardo Viveiros de Castro, Marilyn Strathern, Philippe Descola y Tim Ingold trayendo a la luz otras formas de pensar y vivir el mundo que no inscritas en las dualidades naturaleza versus cultura, humano versus no humano, femenino versus masculino.

PALABRAS CLAVE: Filosofía occident. Dualidades. Potencial científico. Antropología.

ABSTRACT: This article proposes to demonstrate the potential and contributions of Anthropology as a science capable of overcoming the western philosophy of thinking the world by dichotomous and excluding categories. In order to achieve this goal, we used the works of anthropologists Bruno Latour, Eduardo Viveiros de Castro, Marilyn Strathern, Philippe Descola and Tim Ingold, bringing to light other forms of thinking and living the world that are not inscribed in the dualities of nature versus, culture versus human versus non-human, female versus male.

KEYWORDS: Western philosophy. Dualities. Scientific potential. Anthropology. Introdução

${ }^{1}$ Universidade Estadual Paulista (UNESP), Araraquara - SP - Brasil. Graduanda em Ciências Sociais. ORCID: <https://orcid.org/0000-0003-0608-4615>. E-mail: mariilombardi@hotmail.com.

${ }^{2}$ Universidade Estadual Paulista (UNESP), Araraquara - SP - Brasil. Graduanda em Ciências Sociais. ORCID: <https://orcid.org/0000-0003-1980-6007>. E-mail: quel_lujan@ hotmail.com. 
Com sua máxima "penso logo existo", Descartes (2001) tentou unificar todos os conhecimentos humanos sobre bases racionais. Para ele o sujeito (individual) é o sujeito de consciência. A preocupação com a razão repercutiu de tal forma nas ciências em geral que logo estas se sentiram obrigadas a operar sob o paradigma cartesiano. Entender a filosofia de Descartes é de extrema importância para compreender a construção do pensamento ocidental, sistematizado em categorizar através de dicotomias seguindo uma lógica excludente que supõe inferioridades e superioridades, além de estabelecer hierarquias por intermédio da razão, e dessa forma, explicando as coisas a seu próprio modo.

Jean Jacques Rousseau foi um crítico ferrenho de Descartes e de seu sujeito racional. Descartes acreditava na passagem direta da interioridade do homem à exterioridade do mundo, contudo para Rousseau (1999), existem outras sociedades e civilizações que interferem na relação eu-mundo. Em seus escritos, Rousseau (1999) coloca-se contra o Cogito cartesiano expresso na máxima "penso logo existo", realizando questionamentos das evidências do sujeito conhecedor. Conforme Lévi-Strauss (1976) é como se Rousseau antes se questionasse: "sou?", "o que sou?", "sou eu quem pensa?". Seguindo esse raciocínio, a resposta poderia ser "eu é um outro" e com isso Rousseau afirma-se como o grande inventor de uma objetivação radical na relação entre sujeito e objeto. Para Lévi-Strauss (1976), tal objetivação e a ruptura cartesiana foram fundamentais para a invenção das ciências do homem e também para a formulação de sua antropologia estrutural.

Ainda segundo Lévi-Strauss (1976), no pensamento de Rousseau há uma tríplice passagem (e não ruptura) da Natureza para a Cultura, da animalidade à humanidade e do sentimento para o conhecimento, que só foi possível devido à faculdade da "piedade", característica "naturalmente dada" e cultural aos homens, porque é ao mesmo tempo afetiva e racional: é a identificação com o outro pelo simples fato de ele ser um ser vivo. Essa articulação entre o sensível e o racional quebra a racionalidade rígida da filosofia cartesiana. A piedade, para Rousseau, é a base de toda a nossa razão, é a apreensão global de que homens e animais são seres sensíveis. Assim, o autor rebate ao mito de uma dignidade exclusiva do homem e propõe uma identificação com todas as formas de vida, sendo esse o único fundamento possível da moral. Claude Lévi-Strauss (1976) diz-nos que o Discurso sobre a origem e os fundamentos da desigualdade entre os homens pode ser considerado o primeiro tratado geral de etnologia por tratar da relação entre Natureza e Cultura, tema tão fundamental para a Antropologia, além de nos ensinar a olhar para o mais distante (outros povos) e para o mais próximo (nós mesmos), recusando o que nos é próprio à primeira vista, sendo essas uma das características da prática etnográfica. 
Por mais que a Antropologia tenha nascido e crescido dentro da matriz filosófica ocidental - portanto, dicotômica de entendimento - atualmente, esta disciplina nos mostra que há outros mecanismos possíveis de pensamento, e nesse sentido, propõe alternativas para a superação das dualidades ocidentais importadas ao conhecimento científico e cultural que limitam a compreensão do mundo.

\section{As contribuições da Antropologia na superação das dualidades}

A atenção de grandes antropólogos esteve direcionada em questionar as teorias duais presentes na filosofia ocidental e as categorias analíticas que elas impõem. A preocupação antropológica de Eduardo Viveiros de Castro (2002) se deu no sentido de dotar o universo descrito pelos povos das terras da América do Sul através de uma ontologia que escapa, ou torna mais complexo o binômio natureza versus cultura e sobre a qual o corpo tem um papel fundamental de diferenciador ativo de humanidade. A perspectiva dos povos indígenas é ortogonal às noções ocidentais: “o ponto de vista está no corpo, e não no espírito" isso supõe a existência do mundo visto igualmente por todos, mas que é alterável conforme a perspectiva de cada um frente a ele.

Após suas etnografias e de diversos outros pesquisadores sobre os povos indígenas, Viveiros de Castro (2002) defende a necessidade de criticar etnologicamente suas cosmologias internas a fim de acrescentá-los ao debate muito comum de oposição entre natureza e cultura dentro da antropologia. Sua intenção seria de colocar as diversas perspectivas diferentes sobre o que ele denomina Multinaturalismo ameríndio encontrado em vários povos sul americanos, sobretudo nas sociedades do noroeste amazônico, mas também nas regiões da zona setentrional da América do Norte e da Ásia e o Multiculturalismo ocidental moderno.

O perspectivismo consiste em uma concepção indígena que entende a existência de uma diferença entre como os seres humanos veem os outros animais e seres dotados de subjetividades - deuses, espíritos, mortos, habitantes de outros níveis totêmicos, plantas, fenômenos meteorológicos, acidentes geográficos, objetos e artefatos - e como esses seres veem a si próprios e os seres humanos. Aqui, o termo "ver como" está dotado de perspectivas - que não são aplicáveis a todos os animais, mas mais frequentemente aos grandes predadores e carnívoros, ademais, estaria ele relacionado a graus e situações específicas (VIVEIROS DE CASTRO, 2002). 
Em síntese, o pensamento ameríndio entende que há uma humanidade nos animais, e a maneira como esses se manifestam seria apenas "envoltórios" que escondem sua forma humana interna, idêntica à consciência humana, um "esquema corporal humano oculto sob a máscara animal" (VIVEIROS DE CASTRO, 2002. p. 351). Não há aqui uma dimensão de humano x não-humano, existe uma noção virtualmente universal de estado de indiferenciação entre os humanos e os animais: "A dimensão original comum a todos os humanos e animais não é a animalidade, mas a humanidade". Enquanto a antropologia humana compreende que a cultura oculta a animalidade existente nos seres humanos, o pensamento indígena entende que todos os seres do cosmos são humanos de modo não evidente - como afirma Descola (1998), os ameríndios entendem a humanidade enquanto uma condição comum a todos os seres e coisas intersubjetivas.

O antropólogo brasileiro também recupera o conceito de animismo recentemente utilizado por Philippe Descola (1998) ao temer que a noção de perspectivismo pudesse se relacionar com o primeiro. O modo anímico de Descola diz respeito a uma característica presente em sociedades onde o animal é como ele mesmo diz "foco estratégico de objetivação da natureza e de sua socialização". No entanto, enquanto o animismo postula a existência de um caráter social entre as relações humanas e não-humanas, o naturalismo compreende as relações humanas e não-humanas como elas próprias naturais. Há uma relação antagônica a essas dimensões no que diz respeito à natureza e à cultura: o mundo anímico ao compreender que todos os seres cósmicos são dotados de humanidade entendem que tudo que diz respeito à natureza e à cultura é, portanto, social, o que Viveiros de Castro (2002) denomina de modelo "sociocêntrico", pois, faz uso das relações e categorias humanas para mapear o universo. Já o naturalismo ocidental supõe uma dualidade entre natureza e cultura, pois entende que na primeira estaria a primazia da necessidade e na segunda, a primazia da espontaneidade. Dessa forma, a ontologia naturalista concebe a relação de natureza e cultura como natural. Nessa concepção, os humanos são seres em interação com outros seres ecológicos dotados de força tudo isso resguardado pelo campo da biologia-, ao passo que as relações sociais só existem dentro das relações de humanos para com humanos dentro da sociedade.

O conceito de perspectivismo de Viveiros de Castro (2002) se sobrepõe à noção de animismo de Philippe Descola (1998). O animismo, através de uma noção cosmológica não separa o universo da cultura do universo da natureza, compreende o cosmos inteiro animado por um mesmo regime cultural, argumento de algum modo semelhante ao defendido por Bruno Latour (1994). Assim, denominados por Viveiros de Castro enquanto cosmocêntricos, os povos ameríndios provam à ciência ocidental que não há a existência dessa dicotomia entre humanos 
e não-humanos como postulou Lévi-Strauss, ao recuperar um relato sobre como os povos das Grandes Antilhas (1952) entendiam os estrangeiros espanhóis que chegavam à América do lado oposto da fronteira que divide humanos de animais e espíritos- e, portanto, a natureza da cultura.

Em seu tempo, o antropólogo estruturalista ${ }^{33}$ buscou assemelha-los aos ocidentais ao evidenciar que tal como nós eles também distinguiam dicotomicamente os humanos verdadeiros dos não-humanos. No entanto, ao compreender a natureza e a cultura dentro do mesmo ínterim, o animismo reconhece verdadeiramente - não para Descola - a mestiçagem entre humanos e não-humanos, entre sujeitos objetos "a que nós modernos sempre estivemos cegos, por conta de nosso hábito tolo, para não dizer pecaminoso, de pensar por dicotomias." (VIVEIROS DE CASTRO, 2002. p. 370)

Para que fique claro, o pensamento ameríndio entende a cultura como a natureza do Sujeito, apenas através dela é possível experimentar a natureza. E aqui Sujeito pressupõe um ser cuja forma geral é a humanidade, condição comum aos animais e seres humanos: “É Sujeito quem tem alma, e tem alma quem é capaz de um ponto de vista". Dessa forma, em resumo, nas sociedades sul americanas, os corpos é que se diferem, e aqui entra uma grande diferença com o etnocentrismo ocidental. Para Lévi-Strauss, os índios das Grandes Antilhas estavam preocupados em saber se aqueles que vinham além-mar possuíam um corpo que se assemelhasse ao deles, pois já era sabido que eram dotados de alma, analogamente a eles. Ao etnocentrismo, fica o caminho oposto, negar que os seres não ocidentais sejam dotados de alma humana.

Como postulou Tim Ingold (1994), há um caráter especificamente ambíguo da tradição ocidental que divide as noções de humanidade entre "Humankind" (dentro do campo da biologia, que entende o ser humano enquanto um animal tanto quanto os outros) e "Humanity" (dentro do campo das ciências culturais, é uma condição moral que separa seres humanos de animais). Fica à dimensão do espírito o potencial de nos diferenciar, com superioridade, dos outros seres da natureza. Por sua vez, Philippe Descola (1998) procurou traçar um debate a respeito das sensibilidades antropológicas e antropocêntricas através de um paralelo entre a concepção ocidental sobre as relações para com os animais versus a relação dos povos Achuar e outros povos indígenas ameríndios e suas relações entre humanos e animais. Para ele, essa relação com a natureza só poderia ser compreendida na medida que se entendesse que muitos

${ }^{3}$ Sobre esse assunto consultar LÉVI-STRAUSS, Claude. Raça e História, 1952. In: Antropologia Estrutural II, Rio de Janeiro: Tempo Brasileiro, 1976. 
costumes indígenas não condenam a relação de caça, pois tratam o animal em termos muitos distintos daqueles que são familiares aos povos ocidentais. Como já delineado por Viveiros de Castro (2002), esses povos não lidam com a relação humanos e animais através de um dualismo ontológico, há uma noção de "pessoa" que se estende dos humanos aos animais, plantas e até mesmo espíritos, os Sujeitos têm comportamentos e percepções simétricas aos humanos.

Descola (1998) critica o comportamento ocidental de categorizar a caça presente dentro desses grupos enquanto algo condenável moralmente e fruto de más consciências, pois significaria concedê-los um tratamento para com os animais que são próprios do ocidente, fruto das nossas práticas e mentalidade, e que por vezes são bastante contraditórias. Além disso, compreender enquanto um dilema moral, enfrentando-o numa dimensão ética seria dotar as relações ameríndias dentro de um sistema de direitos, obrigações e valores universais. A própria noção de humanidade e sua diferença entre homem e animal é definida como a capacidade de subtrair-se das determinações instintivas, ou seja, isso diz muito sobre a nossa relação para com alguns animais que têm atitudes cognitivas análogas às nossas, os respeitamos pois devemos respeitar a nós mesmos, e segundo Descola, não parece ser esse o critério usado pelos ameríndios.

Já a antropóloga britânica Marilyn Strathern (2014) contribui para o debate ao afirmar que uma das formas de provar para nós mesmos (ocidentais) que construímos uma verdadeira dicotomia entre natureza e cultura é a projeção de tais aspectos nas sociedades estudadas pelas antropólogas e antropólogos. Citando Burridge (1973), mostra que a combinação das possibilidades de participar da "alteridade"' e de, ao mesmo tempo, tratá-la como objeto de estudo, foi o que criou a antropologia. A projeção de aspectos de natureza e de cultura nas sociedades estudadas, segundo Strathern (2014), pode ser estimulada na descoberta de um simbolismo indígena que, à primeira vista, estabelece separações entre os papéis masculinos e femininos ou entre a vida doméstica e a vida selvagem. A antropóloga estuda o caso Hagen para mostrar que entre eles não existe distinção entre natureza e cultura, mas sim uma distinção entre o doméstico e o selvagem. A diferença entre mbo (doméstico) e romi (selvagem) associase às coisas apropriadas para os homens e às coisas apropriadas para as mulheres. A própria distinção Hagen entre doméstico e selvagem (mbo-romi) é inata por ser entendida como um atributo do mundo dado, e não produzido. Esta particularidade no pensamento Hagené, 
segundo a autora, algo que contrasta com a maneira ocidental de constantemente "produzir" a cultura e recriar a relação entre cultura e natureza sucessivamente:

Para eles, o convencional - gramática, relações de parentesco, ordem social, ("norma" e "regra") - é uma distinção inata, motivadora e 'sorrateira' (portanto inexplicável) entre o que é inato e o que é artificial." ([1975] 2010: 143). Para Wagner, os ocidentais criam o mundo incidental ao tentar sistematizá-lo; os povos tribais criam seu universo de convenções sociais inatas ao tentar modificá-lo ou interferir nele" (STRATHERN, 2014. p. 43).

Contudo, para a autora, não é possível atribuir ou reduzir a um sentido único o universo natural ou cultural mesmo no pensamento ocidental pois não há, de fato, uma dicotomia consistente, apenas uma "matriz de contrastes", que é a própria matriz da metafísica ocidental. A oposição entre natureza e cultura não ocorre de modo não estático, e sim numa constante tensão. Desse modo, conforme argumenta Strathern, esses constructos duais giram em torno da noção de que um domínio pode ser controlado, dominado ou colonizado pelo outro. $\mathrm{Na}$ verdade, natureza e cultura possuem uma relação dialética, em que seus significados se alteram em relação às circunstâncias em que se encontram cada domínio. Embora a autora reconheça que a constituição da noção de natureza e cultura é um artifício, em sua opinião, ainda tentase legitima-lo fundamentando-o na própria natureza. Para ela, "o gênero é um operador fundamental nessa transformação" (STRATHERN, 2014. p. 44).

Strathern (2014) utiliza-se do simbolismo masculino-feminino para exemplificar seu argumento: empregamos masculino e feminino num sentido dicotômico, no qual ambos representam a espécie humana, dividida em metades, assim, cada uma delas é caracterizada por aquilo que a outra não é. A partir desse pressuposto, é possível explicar o equacionamento da mulher em consonância com a natureza. Se a cultura é vista como um constructo do homem e superior à natureza, logo, homens são "superiores" às mulheres. Não à toa é comum empregarmos certos adjetivos referidos aos homens como símbolos de cultura (criatividade, antrópico, sociedade, cultural, cultivado) e certos adjetivos às mulheres como símbolos de natureza (instinto, inato, indivíduo, biológico, selvagem). E quando utilizamos adjetivos como símbolos de natureza para o simbolismo masculino, são relativos à natureza básica, ao selvagem, a um ser autoexpressivo, etc. Já para atribuir características que simbolizam um universo cultural às mulheres são: cultivada, artifício superficial, voltado para o outro, etc. Essas são, para Marilyn Strathern (2014), algumas metáforas da cultura ocidental. No entanto, o gênero também atua como "operador simbólico" entre os Hagen, entre eles, as diferenças 
fisiológicas dos humanos são consideradas inatas e independentes da intervenção humana e as relações entre homens e mulheres são diferenciadas, mas consciente de que há um fundo comum entre o que os separa: a alma e as coletividades da cultura. Aí está mais um ponto da dialética entre natureza e cultura que refere-se Strathern (2014).

Antropólogo das ciências e das técnicas, Bruno Latour (1994) nos dá uma hipótese de como se deu a cisão entre natureza e cultura. Segundo a teoria do autor, num primeiro momento, a realidade adentra e absorve em nós através de uma "tradução", que opera por uma mistura entre natureza e cultura, onde se encontram os "híbridos". Já a constituição do mundo dito "moderno" se deu num segundo momento, o de purificação, que separou a natureza e a cultura $^{4}$. No entanto, Latour propõe que entre natureza e sociedade/cultura haja uma mediação feita pelo Império do Centro, e pela possibilidade de olhar para os híbridos e observar sua origem, os "coletivos" são, para ele, mistos entre natureza e cultura. O antropólogo francês exemplifica com Boyle e seu experimento, que pela primeira vez, dá a capacidade de pensar a natureza como criada pela sociedade dentro do laboratório. Outro exemplo dado pelo autor é o do buraco na camada de ozônio: um fenômeno natural e ao mesmo tempo produzido pela ação humana. Este seria, então, um não-humano. Com isso, Latour (1994) questiona mais uma vez as dualidades e dá capacidade de agência aos objetos, mudando a perspectiva de que só a ação humana dá movimento aos objetos.

Mais do que contribuir para o debate sobre indivíduo versus sociedade, humanidade versus animalidade, masculino versus feminino, natureza versus cultura, Bruno Latour (1994) propõe metodologicamente como a Antropologia pode e deve ser a ciência capaz de superar as dicotomias. Segundo Latour, na etnologia indígena, o antropólogo ou a antropóloga não faz a separação entre os elementos, todas as instituições e os repertórios estão misturados na mesma análise. Por "repertórios", o autor compreende três formas de pensar o mundo: a naturalização, ou seja, a reprodução dos fatos da natureza em laboratório, espaço da ciência pura; a socialização, espaço da sociedade e das relações de poder; e por último, a desconstrução, o campo da linguagem. Como não é possível optar por apenas um repertório quando se faz ciência, os três repertórios citados por Latour (1994) só são capazes de repercutir dentro de uma ideia de rede.

4 "Este é todo o paradoxo moderno: se levarmos em consideração os híbridos, estamos apenas diante de mistos de natureza e cultura; se consideramos o trabalho de purificação, estamos diante de uma separação total entre natureza e cultura. É a relação entre os dois processos que eu gostaria de compreender" (LATOUR, 1994 p. 35 ). 
Sua noção de rede pode ser explicada como uma conexão que atravessa os três repertórios da crítica. Inspirado na ideia de rizoma de Deleuze, Latour (1994) propõe uma forma revolucionária e rizomática (resistente, não hierárquica, ramificada) de produção de conhecimento. As redes são reais como na natureza, coletivas como na sociedade e discursivas pois narradas como o discurso. Além disso, a rede seria capaz de romper as fronteiras entre global e local. Outro ponto importante para Latour diz respeito à passagem do tempo que, em sua visão, ocorre em forma de espiral. A passagem linear do tempo constrói dicotomias, ou melhor, assimetrias entre antigos e modernos, vencidos e vencedores. Uma fronteira que Latour procura romper é entre ciência e política, por acreditar não ser mais possível separálas. Por fim, para construção de uma "antropologia simétrica", é preciso tornar a antropologia capaz de estudar o mundo ocidental e a ciência (sem interiorizar e separar os três repertórios), é preciso que a antropologia ocupe a posição intermediária entre o tradicional e o novo, perca a ligação com o exotismo mas ganhe as naturezas, não separe os quase-sujeitos dos quaseobjetos, os humanos dos não-humanos.

\section{Considerações finais}

Procurou-se mostrar neste artigo que as ciências ocidentais surgem fundamentadas na matriz filosófica cartesiana e num primeiro momento buscaram diferenciar o universo da natureza do universo da cultura, dotando o ser humano e as forças sociais enquanto sujeitos potenciais na construção da cultura. Essa dualidade entre natureza e cultura foi transferida para os outros campos de conhecimento, e moldaram uma interação com o mundo baseada em categorizar coisas e relações, como por exemplo a relação entre humanos e não-humanos, indivíduo e sociedade, feminino e masculino. Na prática, essa construção de conhecimento acabou por limitar as apreensões de saber e moldaram uma visão de mundo etnocêntrica e antropocêntrica que exclui outras possíveis interpretações de mundo. O presente artigo preocupou-se em retratar como o debate das dicotomias esteve presente dentro do campo da Antropologia, e como os autores aqui expostos entendem, cada um a seu modo, as limitações que ele impôs.

\section{REFERÊNCIAS}

DESCARTES, René. Discurso do método. 2. ed. São Paulo: Martins Fontes, 2001. 
DESCOLA, Philippe. Estrutura ou sentimento: a relação com o animal na Amazônia. In: Mana, 4 (1), p. 23-45, 1998.

INGOLD, Tim. Humanity and Animality. In: INGOLD, Tim. Companion Encyclopedia of Anthropology. Londres: Routledge, p. 14-32, 1994.

INGOLD, Tim. A evolução da sociedade. In: FABIAN, A. C. (Org.) Evolução, ciência e universo. Bauru: Edusc, 2007.

LATOUR, Bruno. Jamais Fomos Modernos. Ensaio de Antropologia Simétrica. Rio de Janeiro: Ed. 34, 1994.

LÉVI-STRAUSS, Claude. Jean Jacques Rousseau, Fundador das Ciências do Homem. In: Antropologia Estrutural Dois. Rio de Janeiro: Tempo Brasileiro, p. 41-51, 1976.

LÉVI-STRAUSS, Claude. Raça e História. In: Antropologia Estrutural II. Rio de Janeiro: Tempo Brasileiro, 1976.

ROUSSEAU, Jean Jacques. Discurso Sobre a Origem e os Fundamentos da Desigualdade Entre os Homens. São Paulo: Editora Nova Cultural Ltda, 1999.

STRATHERN, Marilyn. Sem natureza, sem cultura: o caso Hagen. O efeito etnográfico e outros ensaios. São Paulo: Cosac \& Naify, 2014.

VIVEIROS DE CASTRO, Eduardo. Perspectivismo e multinaturalismo na América Indígena. In: A inconstância da alma selvagem e outros ensaios de antropologia. São Paulo: Cosac \& Naify, p. 347-399, 2002.

\section{Como referenciar este artigo}

LUIZ, Mariana Lombardi; LEITE, Raquel Lujan Hissa. A contribuição da antropologia na superação das dualidades. Rev. Sem Aspas, Araraquara, v.7, n.2, p. 219-228, jul./dez., 2018. ISSN: 2358-4238. DOI: 10.29373/sas.v7i2.11662

Submetido em: 27/08/2018

Aprovado em: 05/03/2019 